\title{
EPIDEMIOLOGICAL STUDY OF MEASLES IN BIHAR
}

Babita1, Sanjeev Suman², Shankar Prakash ${ }^{3}$.

1. Tutor, Department of Microbiology,Patna Medical College.

2. Senior Resident, Department of Radiology, Patna Medical College Hospital.

3. Professor \& HOD, Department of Microbiology, Patna Medical College

\section{CORRESPONDING AUTHOR:}

Dr. Babita, Patna Medical College,

Patna.

E-mail: drbabitasmn@gmail.com

HOW TO CITE THIS ARTICLE:

Babita, Sanjeev Suman, Shankar Prakash. "Epidemiological Study of Measles in Bihar". Journal of Evolution of Medical and Dental Sciences 2013; Vol2, Issue 26, July 1; Page: 4695-4700.

ABSTRACT: CONTEXT: Measles is one of the leading causes of death in young children despite the availability of safe and effective vaccine. There is need to fasten the immunization project in Bihar in order to decrease the measles outbreak. AIM: The aim of this study was to study the epidemiology of measles in Bihar during September 2011 to December 2012. SETTING AND DESIGNS: One year three month study witch is based on data of measles surveillance project of Bihar. RESULT: This includes the total number of measles case and measles outbreak in Bihar during Sep 2011 to Dec 2012. The total number of measles case were 165(52.7\%) and total number of measles outbreak were 47 . the children that were immunized but developed disease were $22(32.9 \%)$ and the children that were unimmunized and developed disease were 143(57.2\%). eight death were recorded. CONCLUSION: High vaccination coverage with two doses of measles and rubella containing vaccine should be introduced. This will decrease the outbreak and mortality.

INTRODUCTION: Measles is a childhood disease and cause great morbidity and mortality in India and Worldwide. ${ }^{[1]}$ Globally measles is the fifth killer disease among children under five years of age. [2] Its incidence varies from 58 percent in epidemics to 10 to 15 percent without, in a pediatrics age group. [3][4]Many factors are associated to enhance the cause of the disease such as malnutrition, poverty, poor hygiene, overcrowding and above all improper immunization ${ }^{[5]}$ and the truth of the matter is that more than $95 \%$ of the measles death occurs in countries with low socio-economic status and poor health infrastructure. [6]

Measles is an infectious disease of childhood and the mode of infection is through droplet infection. Low immunization causes unnecessary epidemic. [7] The introduction of measles vaccine in to the Universal Immunization Programme (UPI) of the country was in 1985. May be due to this the number of cases came down from 252,000 cases in 1987 to 36900 cases in 2007. [8] In Bihar, the National Family Health Survey (NFHS) in 1993 reported a low coverage level of immunization for children for all vaccines. [9] But then it was seen that in Bihar, once the state with the lowest immunization coverage levels in the country, the proportion of children immunized against 
common childhood disease tripled as polio eradication activities intensified ( from 18.6\% in 2005 to $66.8 \%$ in 2010 ). [10]

MATERIAL AND METHODS: The study was based on the data of measles surveillance project of Bihar. The study was conducted from September 2011 to December 2012. A case of measles was analysed by the project as an epidemiologically confirmed case of measles. It included any person in whom clinician suspects measles infection or any person with cough or coryza (running nose) or conjunctivitis (red eyes). This was investigated as a part of measles only outbreak. This epidemiologically confirmed case along with clinical case definition was send to WHO accredited laboratory. Bihar state has the total population is more than 82 million. Density of population in Bihar is 880 per square kilometers. The state is divided into 38 revenue districts. The measles surveillance project was started in Bihar from September 2011. Under this project an investigation is triggered when -

$\geq 5$ clinical cases of measles in a block in a week.

$\geq 1$ death due to measles in a block in a week.

$\geq 5$ clinical cases in an area boarding several blocks.

A death which occurred within one month of onset of measles was included in the project. The project is initiated by Epidemic Response Team (EPI). The role of ERT is to plan and guide investigation of outbreak and to monitor progress in data collection, compile and analyze data and bring out a final report. The health workers of each area searches house to house to find clinical measles case that have occurred within last three months and list them down. The ERT identifies at least five cases of measles and deputes a medical officer to take the blood specimen. The blood specimen is taken between 4 to 28 days after the onset of rash. Samples are tested against measles and rubella in a WHO accredited laboratory. The result is defined separately as measles only outbreak (at least two samples positive for IgM measles and none for rubella), rubella only outbreak (at least two sample positive for IgM rubella and none for measles) and mixed outbreak (some sample positive for IgM measles and some for IgM rubella). Measles negative samples are tested for rubella.

The epidemiologically linked cases were analysed separately and were related to outbreak like the year and the location of outbreaks, number of cases, number of samples positive for measles death, sex, and vaccination status.

Confirmation of outbreak include the positive measles IgM in at least two blood samples collected during the outbreak and tested in WHO accredited laboratory. Measles negative samples are tested for rubella.

RESULT: OUTBREAK - During the period of September 2011 to December 2012 the total number of clinically suspected measles outbreak were 47 . Of these only 44 (93.1\%) were measles only outbreak and rest $3(6.3 \%)$ of the outbreak were rubella only and mixed outbreak.

The total numbers of epidemiologically linked cases during September 2011 to December 2012 were 313 (50 in 2011 and 263 in 2012). Of these positive samples were 165(52.7\%) and 130 $(41.5 \%)$ were negative and remaining $18(.05 \%)$ samples were equivocal. 
District wise distribution - Among 38 districts in Bihar 16 district had confirmed measles outbreak. The location of outbreaks is shown in figure 1. The district that was severely affected were Supaul, Darbhanga, Vaishali, Saharsa, Madhubani. Table 1 shows the number of outbreaks and number of cases.

Seasonal distribution - The month that had increased number of positive cases during September 2011 to December 2012 were September and December. While again the number of case increased in March, April, May. This is described in Fig 2

Age - Out of the positive cases the cases that were below 5 years of age were 83 $(50.3 \%)$ and $82(49.7 \%)$ were more than 5 years.

Male contributed to 89 (53.9\%) whereas female rate was $76(46.1 \%)$. The cases that were immunized $63(20 \%)$ but developed the disease were 22 (34.9\%). The number of cases that were not immunized were 250 (79.8\%) and among unimmunized cases 143(57.2\%) developed disease.

Discussion

Bihar has 38 revenue district and among them 16 district had confirmed measles outbreak since the implementation of measles surveillance programme. The district such as Supaul, Darbhanga, Vaishali, Saharsa and Madhubani showed severe outbreak. Outbreaks were also seen in Sitamarhi, Banka, Purnia, Samastipur, Kisanganj, Madhepura, Araria and Begusrai. Lacks of hygiene in slums, malnutrition, overcrowding and high illiteracy in the underprivileged slum population were the other reason for the increased risk of measles transmission. Low immunization coverage and poor surveillance system are responsible for measles outbreak in different parts of India. [11] Immunization coverage for the vaccine is low in Bihar. ${ }^{[9]}$ Cases of measles were usually seen during winter and early spring (January to April), [12] August to October [13] but it was observed that high peak was seen in September and December. But again high peak was seen in March, April and May. Among the cases the number of vaccinated person was 63 (20\%) but developed disease was 22 (34.9\%). Rest 250 (79.8\%) were not vaccinated and unvaccinated who developed disease were 143 (57.2\%). The attack rate in vaccinated group was low and in unvaccinated group it was high. [14]If the vaccination coverage were high the number of outbreak was likely to decrease. The commonest reason for non-vaccination was the ignorance of patients about the seriousness of the disease and the need of vaccination. [16] Urgent strengthening of routine immunization services and high quality mass vaccination campaigns against measles are recommended to achieve measles elimination. A safe and effective vaccine exists, and has played a major role in reducing the global number of measles death 548000 to 158000 a year between 2000 and 2011. But more children are yet to be vaccinated. In 2011, 20 million children were worldwide remaining unimmunized. [10]

Among the case that were immunized, 63(20\%), but developed the disease were $22(34.9 \%)$. The number of cases that were not immunized were $250(79.8 \%)$ and among the unimmunized cases, $143(57.2 \%)$ developed disease. This data also shows that the immunization coverage is low. The attack rate in vaccinated group was $34.9 \%$ and attack rate in unvaccinated group was $57.2 \%$. The attack rate was high in unimmunized cases [14] Unvaccinated young children are at highest risk of measles. In 2011 about 84\% of the world's children receive one dose of measles vaccine by their first birthday through routine health services. Two doses of vaccine are recommended to immunity and prevent outbreak, as about $15 \%$ of vaccinated children fail to develop immunity from the first dose. [6] 34.9\% developed measles even though they were vaccinated. It is clear that $79.8 \%$ were not immunized. Unfortunately 8 children died during the 
study. This may be due to serious complication including blindness, encephalitis, severe diarrhoea, ear infection or pneumonia.[14] As high as $10 \%$ of measles case result in death among population with high levels of malnutrition and a lack of adequate health care. [6] More than one third of all measles deaths worldwide (around 56000 in 2011) are among children in India.[10] It was estimated that 54800 children died of measles in 2000. By 2011, a global push resulted in a $71 \%$ reduction in death. Since 2000 with support from the Measles and Rubella Initiative (M \& R Initiative) over 1 billion children were vaccinated in mass vaccination campaigns. Immunization plays a role in decreasing the peak of outbreak and an increasing inter epidemic interval. The need to achieve and sustain high immunization coverage along with strengthening the routine surveillance system in growing slums of cities. The goal of eradication can only be attained by better provision of treatment facilities and high immunization coverage. [18]

Measles do occur in vaccinated group and this could be due to waning immunity of the first dose. So by vaccinating the children by second dose can increase immunity in those who did not develop immunity. [19]

\section{REFERENCES:}

1. Wairegkar N, Chowdhury D, Vaidya S, Sikchi S et al. Molecular Epidemiology of Measles in India, 2005-2010. The Journal of Infectious Disease2011:204:403-413.

2. Gupta SN, Vidya R, Gupta N, Gupta MD. Factors precipitating outbreaks of measles in District of Kangra of North India: A case-control. International Journal of Applied and Basic Medical Research 2011; 1:24-30.

3. Bharti B and Bharti S. Measles in a hilly Hamlet of Northern India. Indian J Paediatric 200; 69:1033-5.

4. World Health Organisation. Expanded Programme on Immunization updates 1993.

5. CDC. Global Measles control and regional elimination. 1998-1999 MMWR 1999; 48:112430.

6. WHO. Fact sheet $\mathrm{N} \circ 286$. Measles February. Available from: http://www.who.int/media centre/factsheets/fs286/en/.

7. Singh J, Kumar A, Rai RN, Khare S, Jain Dc, Bhatia R et al. Widespread outbreak of measles in rural Uttar Pradesh, India, 1996 : High risk areas and groups. Indian Pediatr 1996; 36:249256.

8. UNICEF and Immunization, Immunization Fact sheet, Press centre UNICEF. Available from: http://www.unicef.org/media/medio.46851. htm [last accessed on 2010 Sep 25].

9. Singh P, Yadav RJ. Immunization coverage in Bihar. Indian pediatrics 1998; 35:156-160.

10. WHO. Improving measles control in India, April 2013. Available from: http://www.who.int/features/2013/india-measles/en/.

11. National Institute of communicable Disease (NICD). CD Alert, Measles continuing to remain a major public health problem in India, 2000; 4(5):2-4.

12. Fine PE, Clarkson JA, Measles in England and Wales-1: An analysis of factor underlying seasonal patterns. Int J epidemiol 1982; 11:5-14.

13. Lawrence T, Anish TSN, Vijayakumar K, Suchitra R et al. Epidemiology of measles outbreaks in Kerala, India during 2007-2008. Annals of Tropical Medicine and Public health 2012; 5:89-93. 
14. Khalique N, Ahmad A, Abedi AJ, Ansari M. A Measles outbreak- A study in migrant population in Aligarh, Uttar Pradesh. Indian J Prev. Soc. Med. 2008; 3:168-171.

15. Sharma MK, Bhatia V. Swami HM. Outbreak of measles amongst vaccinated children in a slum of Chandigarh. Indian Journal of Medical Science 2004; 58: 47-53.

16. Desai VK, Kapadia SJ, Kumar P, Nirupam S. Study of Measles Incidence and Vaccination coverage in Slums in Surat City, Indian Journal of Community Medicine 2003;28.

17. Thakur JS, Ratho RK, Bhatia SP, Grover R et al. Measles outbreak in Periurban area of Chandigarh: need for improving vaccine coverage and strengthening surveillance. Indian J pediatr; 2002; 69 (1):633-7.

18. Singh J, Sharma RS, Verghese T. Measles mortality in India. A review of Community Based studies. J Commun. Dis.1994; 26(4):203-14.

19. Dilraj A, Cutts FT, deCastro JF, Wheeler JG, Brown D, Roth C et al. Response to different measles vaccine strains given by aerosol and subcutaneous routes to school chitdren: A randomised trial. Lancet 2000; 355:798-803.

Distribution of measles outbreak in Bihar during Sep 2011 to Dec 2012.

\begin{tabular}{|l|l|l|l|}
\hline Serial No. & District & Outbreak & Number of Cases. \\
\hline 1 & Darbhanga & 9 & 32 \\
\hline 2 & Supaul & 8 & 34 \\
\hline 3 & Vaishali & 3 & 12 \\
\hline 4 & Saharsa & 5 & 22 \\
\hline 5 & Madhubani & 3 & 10 \\
\hline 6 & Sitamarhi & 2 & 10 \\
\hline 7 & Banka & 2 & 9 \\
\hline 8 & Purnia & 2 & 8 \\
\hline 9 & Samastipur & 2 & 6 \\
\hline 10 & Khagaria & 2 & 5 \\
\hline 11 & Madhepura & 3 & 4 \\
\hline 12 & Kisangaj & 1 & 5 \\
\hline 13 & Araria & 1 & 3 \\
\hline 14 & Begusarai & 1 & 2 \\
\hline 15 & Katihar & - & 2 \\
\hline 16 & Sheohar & - & 1 \\
\hline & Total & $\mathbf{4 4}$ & $\mathbf{1 6 5}$ \\
\hline
\end{tabular}

Table 1 Shows number of outbreaks and number of cases. 


\section{ORIGINAL ARTICLE}

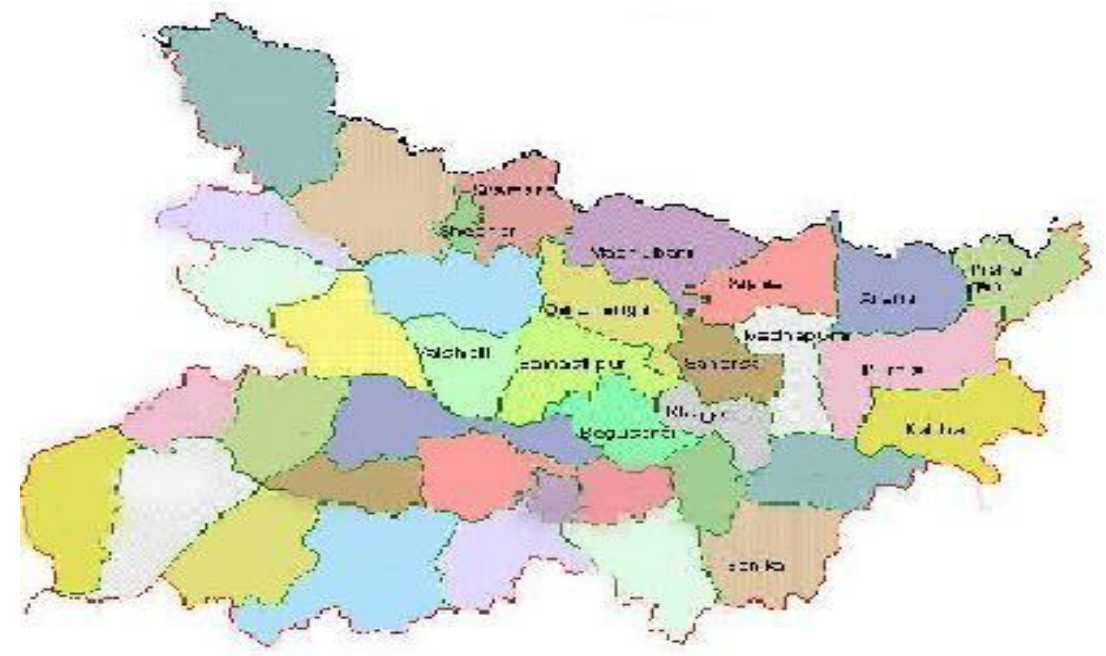

Figure - 1

\section{Figure 2}

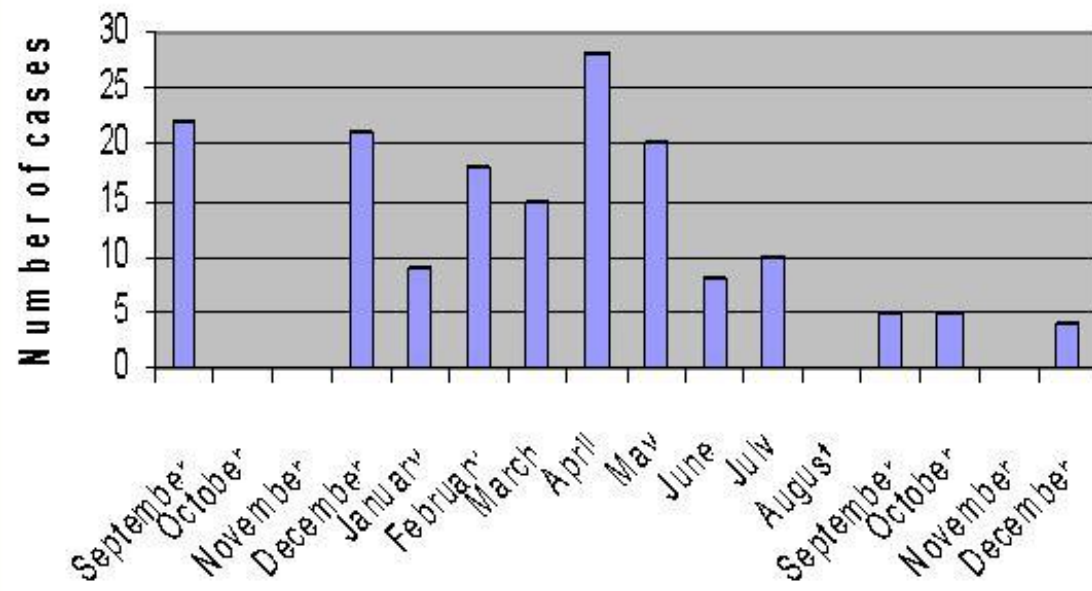

$2011 \cdot 2012$

Monthly distribution of the cases. 